\title{
Determination of Dopamine in Solution of Ascorbic Acid at Graphite-Reinforcement Carbon Electrodes by Differential Pulse Voltammetry
}

\author{
Hiroko KANEKo*, Masahiro YamadA* and Koichi AoKI** \\ *Electrotechnical Laboratory, Umezono, Tsukuba, Ibaraki 305, Japan \\ ** Department of Applied Physics, Faculty of Engineering, Fukui University, \\ Bunkyo, Fukui 910, Japan
}

\begin{abstract}
Cyclic and differential pulse (DP) voltammograms of dopamine (DA) in Ringer's solution were measured at a graphite-reinforcement carbon (GRC) electrode. GRC is available as the lead of mechanical pencils. Cyclic voltammograms of DA exhibited two anodic peaks, at ca. $-0.0 \mathrm{~V}$ and ca. $0.4 \mathrm{~V} v s$. SCE, and a cathodic peak at $0.05 \mathrm{~V}$ vs. SCE in the solution of $\mathrm{pH}$ 6.8. Ascorbic acid (AA) presented an irreversible anodic wave at $0.2 \mathrm{~V}$ at $\mathrm{pH} 6.8$. Voltammograms in the mixed solution of AA and DA were not a simple sum of each voltammogram, and hence were associated with chemical complications between AA and DA. DP voltammograms of the mixed solution had an anodic and a cathodic peak at $c a .0 .05 \mathrm{~V}$, which were stable during 4 days' soaking of the electrode in the solution. The anodic peak height was proportional to the concentration of DA in the range from $5.0 \times 10^{-6}$ to $1.2 \times 10^{-4} \mathrm{~mol} \mathrm{dm}^{-3}$. DA could be determined quantitatively from a calibration curve in the presence of AA from 5 to 20 times larger than DA concentrations.
\end{abstract}

Keywords Dopamine, ascorbic acid, graphite-reinforcement carbon electrodes, differential pulse voltammetry

Physiological actions of dopamine (DA) have been studied in the light of neurotransmission in neural networks and brain. A function of DA is to regulate neural interactions by reducing permeability of gap junctions between adjacent neurons of the same type. A measure of the regulation is the concentration of DA released to the neurons. The concentration of DA has been detected conveniently by a HPLC method ${ }^{1}$, and determined dynamically in response to stimulation of neurons. ${ }^{2,3}$ However, this method is unfavorable owing to poor temporal and poor spatial resolution. Excellent spatial resolution is required for in vivo measurements because released DA is localized in neurons or neural layers.

An alternative of the in vivo detection is an electrochemical monitoring at microelectrodes such as carbon paste $^{4-16}$, carbon fiber ${ }^{11,17-34,52}$, glassy carbon ${ }^{35-39}$, platinum $^{22,40,41}$, epoxied graphite ${ }^{42-46}$, and specifically synthesized carbon electrodes. ${ }^{47,48}$ Since DA in central nervous systems coexists with ascorbic acid (AA) whose redox potential is often similar to the potential of $D A$, improvement of the selectivity of DA against AA has been an analytical target. The improvement has frequently been made by the electrochemical pretreatment developed by Gonon et al. ${ }^{20,23}$ and Falat $e t$ al..$^{43}$

It has been reported ${ }^{47,49}$ that a graphite-reinforcement carbon (GRC), commercially available as lead of mechanical pencils with diameter of $0.2-0.9 \mathrm{~mm}$, exhibits better voltammetric features in practical use than other carbon electrodes. Since the GRC is composed of almost pure carbon without heavy metals, it is not toxic to living tissues. The GRC electrode is strong mechanically and easy to handle compared with pyrolytic graphite and carbon paste electrodes, and is not so rigid in mechanical processes as a glassy carbon electrode. Since the highly quality-controlled GRC is available and inexpensive, it can be used as a disposable electrode. These features may fit conditions of in vivo voltammetric electrodes.

In this article, we examine the voltammetric behavior of DA at the GRC electrode, aiming at the improvement of selectivity from AA and quantitative determination of DA in Ringer's solution.

\section{Experimental}

\section{GRC electrodes}

Leads of mechanical pencils (Mitsubishi Pencil Co. Ltd., Tokyo) $0.5 \mathrm{~mm}$ HB in nominal diameter were used for GRC electrodes. The diameter measured by a micrometer was $0.555 \pm 0.005 \mathrm{~mm}$. A technical note ${ }^{50}$ has reported that these leads were made by dispersing $75-80 \%$ natural graphite into a mixture of $25-20 \%$ 
organic binder, dehydrating the graphite rods at 100 $300^{\circ} \mathrm{C}$, and finally sintering them at $c a .1000^{\circ} \mathrm{C}$ under inert gas atmosphere. Impurity concentrations in the lead determined by the JIS method ${ }^{51}$ were under $2.05 \mathrm{ppm} \mathrm{Cd}, 1.20 \mathrm{ppm} \mathrm{Sb}$ and $0.65 \mathrm{ppm}$ As. Electrical contact to the GRC electrode was made with conductive epoxy cement. The GRC was sheathed with a tip of a plastic pipet into which epoxy resin was stuffed in advance. Polishing of the GRC electrode was done with soft paper or emery paper E\#1500.

\section{Reagent}

Ringer's solution for carp was a mixture of $28 \mathrm{mmol}$ $\mathrm{dm}^{-3}(\mathrm{mM})$ sodium bicarbonate, $1 \mathrm{mM}$ calcium chloride, $102 \mathrm{mM}$ sodium chloride, $5 \mathrm{mM}$ glucose, $2.6 \mathrm{mM}$ potassium chloride and $1 \mathrm{mM}$ magnesium chloride with $\mathrm{pH} 8.1^{2}$ prepared with deoxygenerated water. All chemicals were of analytical grade. DA-HCl (Tokyo Kasei Co. Ltd.) and AA were dissolved in the Ringer's solution to prepare $0.01 \mathrm{M}$ DA with $0.1 \mathrm{M}$ AA stock solutions.

\section{Measurements}

Voltammograms were measured with a Yanaco P1100 polarograph in atmosphere. Deaeration of the solution was not made because of mimicking in vivo measurements under oxygen-rich conditions. Reference and counter electrodes were a saturated calomel electrode (SCE) and a platinum wire, respectively. After electrochemical measurements, the $\mathrm{pH}$ of the solution was checked with a Toa Dempa HM-18E pH meter.

\section{Results and Discussion}

\section{Voltammetric behavior of $D A$ and $A A$}

Cyclic voltammograms of $1 \mathrm{mM}$ DA in the Ringer's solution without AA at the polished (-) and the unpolished (- -) GRC electrodes are showen in Fig. 1. Voltammograms at the polished electrode had two welldefined cathodic waves $(0-0.03$ and $-0.5--0.4 \mathrm{~V}$ vs. SCE), a large anodic wave $(0.4-0.6 \mathrm{~V} v$ v. SCE), and two or three small anodic waves $(-0.3--0.2 \mathrm{~V} v s$. SCE). Those at the unpolished electrode showed two vague cathodic waves and two anodic waves of which the potentials were different from those at the polished electrode. Obviously, the polished and the unpolished electrodes are different in electrochemical activity, especially for the anodic process. Deaeration of the solution diminished the cathodic wave at $-0.5 \mathrm{~V}$. Thus the wave involves a reduction of oxygen dissolved in the solution.

The background-corrected peak current at the first cathodic wave was proportional to the potential sweep rate, $v$. Therefore the wave is associated with adsorption. Net current of the anodic waves could not be determined unequivocally from the background current owing to the preceding small waves and fast

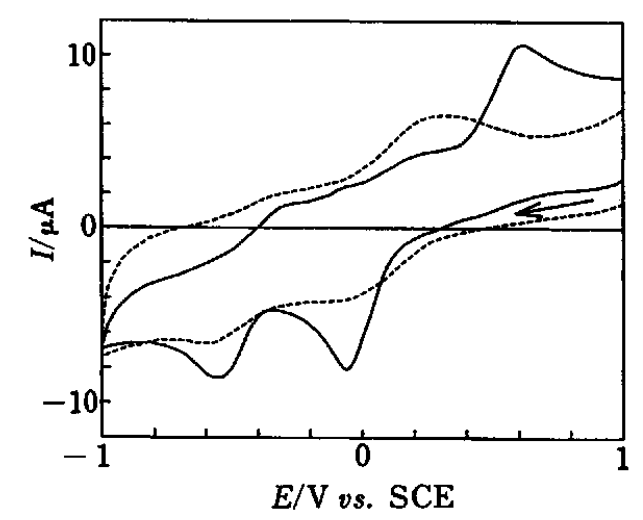

Fig. I Cyclic voltammograms of $1 \mathrm{mM} \mathrm{DA}$ at $v=0.2 \mathrm{~V} / \mathrm{s}$ in the Ringer's solution at the polished (-) and the unpolished (--) GRC electrodes $2 \mathrm{~mm}$ in length. The arrow denotes the direction of the potential scan.

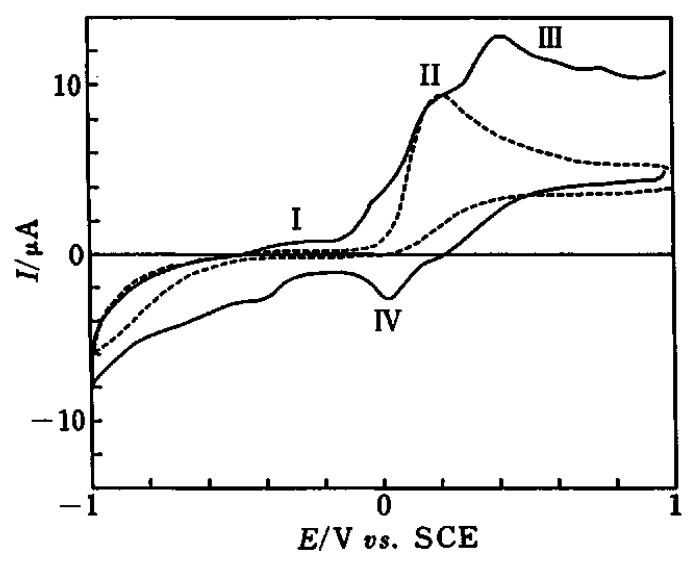

Fig. 2 Cyclic voltammograms of $10 \mathrm{mM}$ AA (---) and of the mixed solution ( $\mathrm{pH} \mathrm{6.8)}$ of $10 \mathrm{mM}$ AA and $2.8 \mathrm{mM} \mathrm{DA}(-)$ in the Ringer's solution at the polished GRC electrode for $v=0.5 \mathrm{~V} / \mathrm{s}$.

degradation of the waves.

Figure 2 shows cyclic voltammograms of $10 \mathrm{mM}$ AA in the presence (-) of $2.8 \mathrm{mM} \mathrm{DA}$ and in the absence (- -) of DA at the polished GRC electrode. The voltammogram of AA (--) lost corresponding cathodic waves and hence was irreversible. The voltammogram in the mixed solution $(-)$ of DA and AA seems to be roughly a simple sum of the wave of only AA and that of only DA. However, this is not the case, as will be discussed in the next section.

Figure 3 shows differential pulse (DP) voltammograms of DA at various concentrations of AA. Waves of interest are the anodic peaks at -0.07 and 0.08 and the cathodic peak at $c a .0 .12 \mathrm{~V}$. These waves correspond to waves II, III and IV in Fig. 2, respectively. Background-corrected peak heights of wave I had a linear relation to concentrations of $\mathrm{AA}$ with a large intercept. 


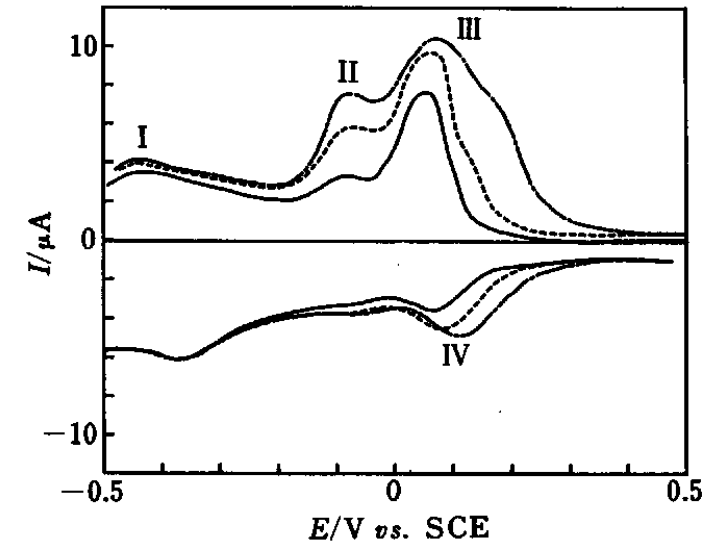

Fig. 3 Differential pulse voltammograms of $0.03 \mathrm{mM}$ DA in the Ringer's solutions involving $0.3 \mathrm{mM}(-), 0.7 \mathrm{mM}(--)$ and $1.3 \mathrm{mM}(-\cdot-) \mathrm{AA}$ at a polished GRC electrode $7 \mathrm{~mm}$ in length under the following pulse conditions: pulse amplitude $=50 \mathrm{mV}, \nu=10 \mathrm{mV} / \mathrm{s}$, pulse duration (drop time) $=$ $0.5 \mathrm{~s}$, sampling time $=50 \mathrm{~ms}$.

On the contrary, waves III and IV exhibited concave variations with high concentrations of AA. Thus these waves do not rely upon the direct charge transfer of AA but may occur indirectly via the charge transfer of DA. Wave II was roughly proportional to concentrations of $\mathrm{AA}$, and hence is ascribed to the oxidation of AA.

\section{Determination of $D A$ by differential pulse voltammetry}

Although pretreated carbon fiber electrodes have been employed for determination of DA, they are often associated with non-durability, poor reproducibility and degradation of the electrode activity because of adsorption of $\mathrm{DA}^{28}$ and chemical complications ${ }^{18}$. Durability and reproducibility of GRC electrode were examined by soaking the GRC electrode in the mixed solutions for a long time and then by conducting voltammetry. The background currents decreased and waves I and II disappeared during the soak, as shown in Fig. 4. The four days' soak caused neither the peaks to broaden nor the peak heights of III and IV to diminish. Therefore the GRC electrodes are useful for long-term measurement of DA by use of the peak heights of waves III and IV.

Peak heights of III and IV increased with an increase in concentrations of DA. However, they varied with high concentrations of $\mathrm{AA}$ in a complicated manner. If concentrations of AA were 20 times larger than those of DA, the wave of AA could be diminished by holding the potential between the oxidation potentials of $\mathrm{AA}$ and DA. ${ }^{52}$ When concentrations of AA were five times larger than those of DA, the peak heights of III and IV were proportional to concentrations of DA in the range from $5.0 \times 10^{-6}$ to $1.2 \times 10^{-4} \mathrm{M}$. Then they are expressed by $j_{\mathrm{III}}=2.0 c$ and $j_{\mathrm{IV}}=1.21 c$, where $j_{\mathrm{III}}$ and $j_{\mathrm{IV}}$ are current densities $\left(\mu \mathrm{A} / \mathrm{cm}^{2}\right)$ of peak currents of III and IV, respectively, and $c$ is the concentration $(\mu \mathrm{M})$ of DA.

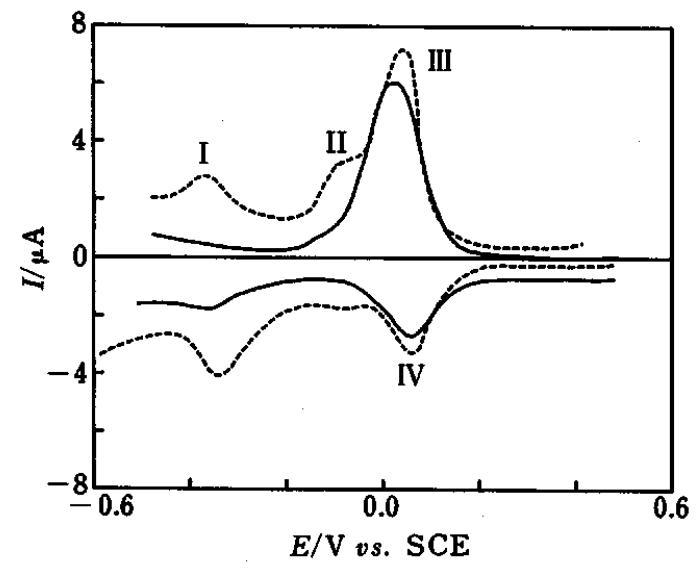

Fig. 4 Time-dependence of DP voltammograms in the fresh solution (--) involving $0.05 \mathrm{mM} \mathrm{DA}$ and $0.5 \mathrm{mM} \mathrm{AA}$, and in the solution ( $\mathrm{pH} 7.9$ ) left for $4 \mathrm{~d}$ in light at $22^{\circ} \mathrm{C}(-)$. Electrochemical conditions were the same as in Fig. 3.

In conclusion, DA could be quantitatively determined from peak heights of III and IV of differential pulse voltammograms at the GRC electrode in the solution involving AA once a calibration curve has been obtained in advance. These waves were discriminated against the oxidation wave (II) of AA. This measurement does not need a specific pretreatment except for simple mechanical polishing. Reproducibility and durability of the measurement were ensured for several days' continuous use without significant degradation of the GRC electrode. Therefore the GRC electrode is superior to other voltammetric carbon electrodes in reproducibility, durability and stability for determination of DA. It is, however, too thick for implantation in living tissues at present. An effort will be made to miniaturize the GRC electrode.

\section{References}

1. M. Kirsch and H. -J. Wagner, Vision Res., 29, 147 (1989).

2. M. Yamada and T. Saito, Biomed. Res. Suppl., 2, 125 (1989).

3. Y. Shigematsu and M. Yamada, Neurosci. Res. Suppl., 8, S69 (1988).

4. M. D. Hawley, S. V. Tatawawadi, S. Piekarski and R. N. Adams, J. Am. Chem. Soc., 89, 447 (1967).

5. R. L. McCreery, R. Dreiling and R. N. Adams, Brain Res., 73, 23 (1974).

6. R. N. Adams, Anal. Chem., 48, 1126A (1976).

7. R. M. Wightman, E. Strope, P. Plotsky, R. N. Adams, Brain Res., 159, 55 (1978).

8. H. Y. Cheng, J. Schenk, R. Huff and R. N. Adams, J. Electroanal. Chem. Interfacial Electrochem., 100, 23 (1979).

9. A. Marsden, J. Conti, E. Strope, G. Curzon and R. N. Adams, Brain Res., 171, 85 (1979).

10. R. Huff, R. N. Adams and C. O. Rutledge, Brain Res., 173, 369 (1979).

11. M. A. Dayton, J. C. Brown, K. J. Stutts and R. M. 
Wightman, Anal. Chem., 52, 946 (1980).

12. K. Ravichandran and R. P. Baldwin, Anal. Chem., 55, 1586 (1983).

13. E. J. Caliguri and I. N. Mefford, Brain Res., 296, 156 (1984).

14. M. R. Deakin and R. M. Wightman, J. Electroanal. Chem. Interfacial Electrochem., 206, 167 (1986).

15. M. B. Gelbert and D. J. Curran, Anal. Chem., 58, 1028 (1986).

16. M. E. Rice, B. Morghadaam, C. R. Creveling and K. L. Kirk, Anal. Chem., 59, 1534 (1987).

17. J. L. Ponchon, R. Cespuglio, F. Gonon, M. Jouvet and J. F. Pujol, Anal. Chem., 51, 1483 (1979).

18. M. A. Dayton, A. G. Ewing and R. M. Wightman, Anal. Chem., 52, 2392 (1980).

19. K. Fox, M. Armstrong-James and J. Miller, J. Neurosci. Methods, 3, 37 (1980).

20. F. G. Gonon, C. M. Fombarlet, M. J. Buda and J. F. Pujol, Anal. Chem., 53, 1386 (1981).

21. P. M. Kovach, A. G. Ewing, R. L. Wilson and R. M. Wightman, J. Neurosci. Methods, 10, 215 (1984).

22. J. O. Howell and R. M. Wightman, Anal. Chem., 56, 524 (1984).

23. F. G. Gonon, F. Navarre and M. J. Buda, Anal. Chem., 56, 573 (1984).

24. R. L. Wilson and R. M. Wightman, Brain Res., 339, 219 (1985).

25. T. W. Gardiner, M. Armstrong-James, A. W. Caan, R. M. Wightman and G. V. Rebec, Brain Res., 344, 181 (1985).

26. A. Akiyama, T. Kato, K. Ishi and E. Yasuda, Anal. Chem., 57, 1518 (1985).

27. F. Marcenac and F. Gonon, Anal. Chem., 57, 1778 (1985)

28. S. Sujaritvanichpong, K. Aoki, K. Tokuda and H. Matsuda, J. Electroanal. Chem. Interfacial Electrochem., 198, 195 (1986).

29. W. G. Kuhr and R. M. Wightman, Brain Res., 381, 168 (1986).

30. A. Meulemans, B. Poulain, G. Baux, L. Tauc and D. Henzel, Anal. Chem., 58, 2088 (1986).

31. R. S. Kelly and R. M. Wightman, Anal. Chim. Acta, 187, 79 (1986).

32. P. M. Kovach, M. R. Deakin and R. M. Wightman, J.
Phys. Chem., 90, 4612 (1986).

33. A. C. Michael and J. B. Justice, Jr., Anal. Chem., 59, 405 (1987).

34. R. M. Wightman, L. J. May and A. C. Michael, Anal. Chem., 60, 769A (1988).

35. C. Ueda, D. C-S. Tse and T. Kuwana, Anal. Chem., 54, 850 (1982).

36. A. N. K. Lau and L. L. Miller, J. Am. Chem. Soc., 105, 5271 (1983).

37. J. F. Rusling, Anal. Chem., 56, 575 (1984).

38. D. T. Fagan, I-F. Hu and T. Kuwana, Anal. Chem., 57, 2759 (1985).

39. R. A. Saraceno, C. E. Engstrom, M. Rose and A. G. Ewing, Anal. Chem., 61, 560 (1989).

40. R. F. Lane and A. T. Hubbard, Anal. Chem., 48, 1287 (1976).

41. R. R. Fike and D. J. Curran, Anal. Chem., 49, 1205 (1977).

42. H. Jaegfeldt, A. B. C. Torstensson, L. G. O. Gorton and G. Johansson, Anal. Chem., 53, 1979 (1981).

43. L. Falat and H-Y. Cheng, Anal. Chem., 54, 2108 (1982).

44. J. O. Schenk, E. Miller, M. E. Rice and R. N. Adams, Brain Res., 227, 1 (1983).

45. G. A. Gerhardt, A. F. Oke, G. Nagy, B. Morghaddam and R. N. Adams, Brain Res., 290, 390 (1984).

46. G. Nagy G. A. Gerhardt, A. F. Oke, M. E. Rice, R. M. Adams, R. B. Moore, M. N. Szentirmay and C. R. Martin, J. Electroanal. Chem. Interfacial Electrochem., 188, 85 (1985).

47. S. Sujaritvanichpong and K. Aoki, Electroanal., 1397 (1989).

48. J. L. Messner and R. C. Engstrom, Anal. Chem., 53, 128 (1981).

49. K. Aoki, T. Okamoto, H. Kaneko, K. Nozaki and A. Negishi, J. Electroanal. Chem. Interfacial Electrochem., 263, 323 (1989).

50. T. Kawakubo, Kagaku Gijutsushi, 10, 1 (1982).

51. JIS S 6019 (1983), 6005 (1984).

52. M. Ikeda, H. Miyazaki, N. Mugitani and A. Matsushita, Neurosci. Res., 1, 171 (1984).

(Received December 7, 1989) (Accepted April 10, 1990) 